\title{
Spermatogenesis, gonadal sperm reserves and fertility of rabbits fed micro doses of fumonisin
}

\author{
F.A. Gbore ${ }^{1,2}$, E. O. Ewuola', J. T. Ogunlade ${ }^{2}$, K. O. Idahor ${ }^{2}$, A. O. Salako ${ }^{2}$ and \\ G. N. Egbunike ${ }^{2}$ \\ 'Department of Environmental Biologn and Fisheries. Adekunle Ajasin Lniversity, Akungha-Akoko, Nigerit \\ 'Animal Physiology Laboratory, Department of Animal Science, Lniversity of Ibadan, Ibadan, Nigeria.
}

\begin{abstract}
The effects of micro doses of dietary fumonisin, a metabolite of Fusarium verticillioides, on spermatogenesis, gonadal sperm reserves and fertility of rabbits were studied. Relative paired testis weight; sperm production rate and sperm storage potential were not adversely affected in rabbits which were exposed to varied minule levels of dietary fumonisin of ahout $153-161 \mathrm{\mu g} / \mathrm{kg}$ body weight/day over a period of 8 weeks. The toxin also failed to exert any influence $(P>0.05)$ on seminiferous tubular diameter and volume percent of testicular elements. Male fertility as evidenced by conception rate, litter size and embrvo survival and normalcy was also not affected $(P>0.05)$. However, the frequency of occurrence of stages 11 and VIII of the cycle of the seminiferous epithelium were significantly $(P<0.05)$ influenced with increased dietary fumonis in levels. The results suggest that the ingestion of Fusarium-infected feed that would result in the liberation of about $153 \mu \mathrm{g}$ of fimonisin/kg of body weight per day for a short time may not influence spermatogenesis, fertility in the male or the normalcy of the resulting foetuses.
\end{abstract}

Key words: $\quad$ Rabbits, Spermatogenesis, Gonadal Sperm Reserves, Fertility and Fumonisin.

\section{Introduction}

Available data on livestock production in Nigeria clearly indicate that we are far from the biological potential for rate and efficiency of gain, fertility and breeding efficiency. As the demand for animal flesh continues to soar, the necessity for increasing the reproductive efficiency of livestock becomes more evident since this may be the area where man can expect the most significant economic achievements in livestock production. Among other factors; nutrition plays a very important role in the regulation of the reproductive cfficiency of animals. Most of the ingredients for ration formulation however contain some obnoxious materials. such as mycotoxins, which have been reported (Egbunike, 1995) not to be conducive to reproduction. Toxins with oestrogenic effects for example, have been reported to impede breeding (Petzinger and Weindenbach, 2002).

Fusarium verticillioides (Sacc.) Nirenberg is one of the most prevalent fungi associated with human and animal dietary staples such as maize (Marasas et al., 1984; Nelson et al., 1991). This species of fungus produces the novel mycotoxin, fumonisin, and Shephard et al. (1996) reported that maize is the only commodity that contains significant amounts of fumonisin, and the importance of this ingredient in the food of man 
and his livestock cannot be overemphasized. Hence, the potential for fumonisins to be found in feeds and foodstuffs is high.

The carcinogenicity, hepatotoxicity and mutagenicity as well as the effects on feed intake and body weight gain by dietary fumonisins in animals have been well documented (Marasas et al., 1988; Harrison et al, 1990; Kellerman et al., 1990; Gelderblom et al., 1991; Colvin and Harrison, 1992). However, interest in these areas had far outweighed those in the effect of fumonisins on the reproductive efficiency of animals.

Concern about the reproductive and developmental effects of fumonisins originated with the observation of abortions in pregnant sows fed fumonisin-contaminated dicts (Harrison et al., 1990) and the report of Bradlaw et al. (1994) that $1.8 \mu \mathrm{g}$ fumonisin $/ \mathrm{ml}$ inhibited reaggregation and growth of chicken embryo neural retina cells, a commonly used in vitro assay for screening potential developmental toxins.

With the above in mind, and the fact that reproductive inefficiency is recognised as the most costly and limiting constraint to efficient animal production, the present investigation was designed with the aims of evaluating the effects of micro doses of fumonisin on spermatogenesis, gonadal sperm reserves and male fertility in the rabbit.

\section{Materials and Methods}

Thirty crosses of adult bucks aged 20-24 weeks weighing between 1000 and $1650 \mathrm{~g}$ were randomly and equally, by live weight, in a completely randomized design assigned to three treatments of low. medium and high $F$. verticillioidesinfected maize-based diets containing 1960, 2080 and $2190 \mu \mathrm{g}$ fumonisin $/ \mathrm{kg}$ respectively, with five rep!icates each.
After the 8-week feeding trial, 5 males per treatment were used to mate untreated female rabbits at the rate of one male to two females. Thereafter, all the male rabbits were sacrificed by stunning and decapitation. right testis dissected and processed as described by Egbunike and Steinbach (1972). Seminiferous tubular diameters were measured following the procedure of Egbunike and Steinbach (1972) and the mean tubular diameter for each animal was calculated from duplicate measurements of 20 round tubules per testis. Sperm production rates were determined by quantitative testicular histology as outlined by Swierstra (1966) and slightly modified by Egbunike and Steinbach (1972). The lifespan of the spermatids with round nuclei was estimated to be 7.32 days from the lengths and cellular associations of the different stages of the cycle of seminiferous epithelium (Ortavant, 1959) and the duration of the whole cycle was 12.0) days (Clermont et al., 1959). The evaluation of the sperm storage potential of the experimental male rabbits involved direct haemocytometer counts of homogenates of testes after $1: 40(\mathrm{v} / \mathrm{v})$ dilution in $0.154 \mathrm{M}-\mathrm{NaCl}$ (Egbunike et al., 1976).

To determine the fertility rates, the mated female rabbits were sacrificed at the end of the first trimester ( 10 days post coilum) and their uteri cut open longitudinally to clieck for conception, count the embryos therein and measure the crown-rump lengths of the embryos.

The data were subjected to statistical analysis using analysis of variance procedure of SAS (1999). The treatment means were compared using the Duncan's procedure of the same software.

\section{Results}

The relative paired testes weight (expressed as percentage of live weight), seminiferous tubule dianeter, volume percent of testicular elements. 
the frequency of occurrence of the stages of the cycle of seminiferous epithelium, except stages II and VIII, daily sperm production rate and the efficiency of spermatogenesis (daily sperm production per $\mathrm{g}$ testis) and sperm storage potentials did not differ significantly $(P>0.05)$ among the treatments (Table 1). The frequency. of occurrence of stages II and VIll of the seminiferous epithelial cycle significantly $(\mathrm{P}<0.05)$ decreased and increased. respectively with increased dietary fumonisin levels.

Similarly, the fertility in the three treatments was not significantly different $(\mathrm{P}>0.05)$. Table 2 summarises the effect which breeding female rabbits with males that had consumed varied micro doses of dietary fumonisin had on their fertility. There were no significant differences $(P>0.05)$ in litter size 10 days post coitum. Crownrump length and the survival rate of the embryo were similar $(P>0.05)$ even though the ovulation rates of the females were likewise similar across the treatments $(12.52 \pm 1.22$ ova shed).

\section{Discussion}

Earlier studies have established that testicular weight and sperm production are highly related (Swierstra, 1966; Egbunike, 1973). In the present study, the relative paired testes weight, gonadal sperm storage potentials, seminiferous tubular diameter and volume percent of testicular elements of rabbits fed fumonisin-contaminated

Tahle 1: Fffect of dietary fum onisin on testis function of rabbits (No can 4 SEM ${ }^{*}$ )

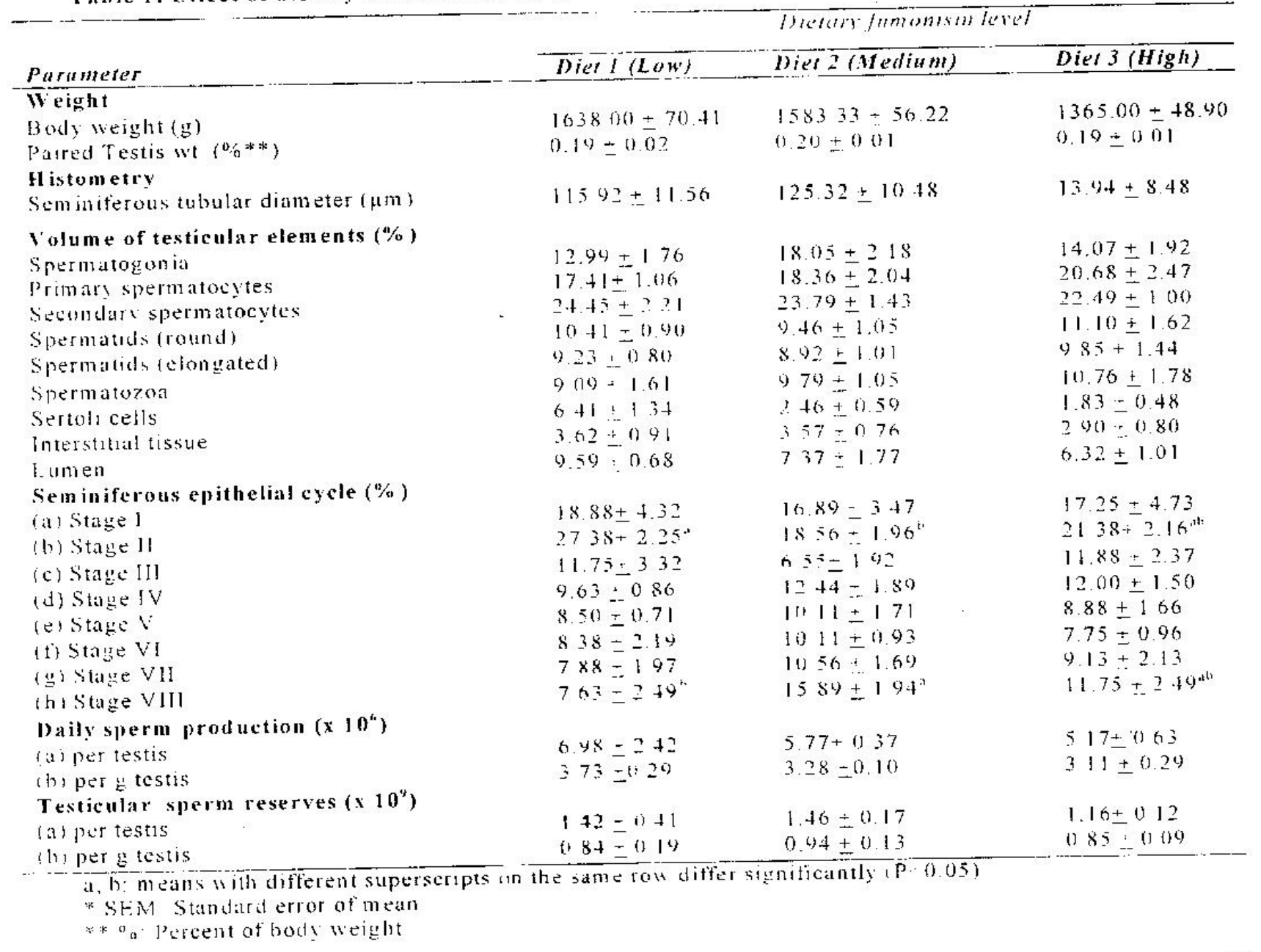


diets were unaffected by the toxin. It is known that the kinetics of spermatogenesis is species specific (Swierstra and Foote, 1963). Therefore, contrary to the gross degenerative changes observed in rats exposed to aflatoxin (Jayaraj et al., 1968), all rabbits in the present study exhibited active spermatogenesis as indicated by the active divisions of the spermatocytes as well as the normal cellular associations in the seminiferous tubules. Also that the first four stages of the seminiferous epithelial cycle (Table 1) constituted over $50 \%$ of the cycle length, which agreed with the report of Egbunike et al. (1985), is an indication that the kinetics of spermatogenesis and hence sperm production were not impaired by the dietary fumonisin levels in the trial since sperm production rates are determined by the kinetics of spermatogenesis as reflected by the seminiferous epithelial cycle. This arose from the significant decrease and increase in the durations of stages II and VIII, respectivcly with increased dictary fumonisin levels indicating that spermatid and spermatocytes maturations are enhanced and delayed, respectively. However, daily sperm production tended to decrease with increased dietary fumonisin.

Finn (1963) whose results indicated that the male influence on litter size was a characteristic of the males and was not due to the male-female interaction had studied the influence of the male on litter size. In the present study, the micro doses of the toxin which the male rabbits were exposed to failed to influence conception rate, litter size, embryo normalcy and mortality. The results corruborate the report of Voss et al. (1996), that no reproductive effects were obscrved in males and females exposed to about 3-4mg fumonisin $\mathrm{B} / \mathrm{kg}$ body weight /day prior to and during mating, gestational and lactational phases of the study. Also, no developmental effects were found in the foetus during any phase of the study.

That these rabbits did not suffer adversely from the dietary toxin exposure may have been due to their nutritional status since malnutrition has been claimed to enhance the susceptibility of animals to lower concentrations of food-borne mycotoxins such as fumonisin (Nelson et al., 1993 ) and so affect their reproductive efficiency

Table 2: Fffects of dietury fumonisin on the fertility of rabbits (Mean $\pm S E M^{*}$ )

\begin{tabular}{|c|c|c|c|}
\hline \multirow[b]{2}{*}{ Parameters } & \multicolumn{3}{|c|}{ Dictary fumonisin level } \\
\hline & Diet I (Low) & Diet 2 (Medium) & Diet 3 (High) \\
\hline Ovulation rate & $14.33 \pm 1.30$ & $11.06 \pm 1.28$ & $12.17 \pm 1.10$ \\
\hline Conception rate $(\%)$ & $20.00 \pm 12.25$ & $10.00+10.00$ & $40.00 \pm 18.00$ \\
\hline Litter size & $2.00 \pm 1.26$ & $0.80 \pm 0.08$ & $5.20 \pm 2.18$ \\
\hline Embryo survival rate $(\%)$ & $50.00 \pm 5.00$ & $25.00 \pm 0.01$ & $69.63 \pm 2.50$ \\
\hline Foetal $\mathrm{CR}^{* *}$ length ( $\left.\mathrm{cm}\right)$ & $2.70 \pm 0.003$ & $4.70 \pm 0.004$ & $3.34 \pm 0.14$ \\
\hline
\end{tabular}

* SEMI : Standart arror of mean

*2R: Cr.r.rimp. 
(Panda et al., 1970). Similarly, the dose and period of exposure may have been accountable for the failure of the toxin to influence all the parameters evaluated, as time-and dose -dependent embryopathic and embryocidal effects of fumonisin $B_{1}$ injected into fertile chicken eggs have been reported (Javed et al., 1993).

\section{Conclusion}

Rabbits mistakenly fed for a short time with rich diet lightly contaminated by Fusarium verticillioides (which would produce about 153 $\mu \mathrm{g}$ of fumonisin per $\mathrm{kg}$ body weight) may not suffer any loss in reproductive efficiency. An investigation of the effects of the dietary fumonisin over a longer period will be necessary in order to evaluate the amount of damage, if any, and the rate of recovery thereafter.

\section{References}

Bradlaw, .l., Pritchard, D., Flynn, T., Eppley, R. and Stack, M. (1994). In vitro assessment of fumonisin $\mathrm{B}$, toxicity using reaggregate cultures of chick embryo neural retina cells (CERC). In Vitro Cell Dev. Biol., 30A: 92.

Clermont, Y., Leblond, C.P. and Messier, B. (1959). Durée du cycle de l'épithélium seminal du rat. Arch. Anat. Micros. Morph. Exp., 48: 37-55.

Colvin, B.M. and Harrison, L.R. (1992). Fumonisin-induced pulmonary edema and hydrothorax in swine. Mycopathologia, 117: 79-82

Egbunike, G.N. (1973). Effects of age and season on the spermatogenic potentials of boars in Ibadan. Ph.D. Thesis, University of Ibadan, Ibadan.
Egbunike, G.N. and Steinbach, J. (1972). Age changes in the testicular function of boars reared in a tropical environment. Proc. $7^{\text {th }}$ Intern. Cong. Anim. Reprod. Artif. Insem. Munich.Vol. III, 2087 2090.

Egbunike, GN., Holtz, W. and Smidt, D. (1976). Reproductive capacity of German Landrace boars. I1. Sperm production rates as determined by quantitative testicular histology and from gonadal sperm reserves. Zuchthygiene, 11:35-37.

Egbunike, G.N., Togun, V.A. and Agiang, E.A. (1985). Sperm production in ruminants in hot humid climates. World Rev. Anim. Prod., Vol. XXI, No 3: 11-17.

Egbunike, G. N. (1995). A toast for spermatozoa: One half of the story of mammalian life. An Inaugural Lecture Delivered at the University of Ibadan, Ibadan on Thursday, the $11^{\text {th }}$ of May, 1995.

Finn, $\dot{\mathbf{C} . A . ~(1963) . ~ I n f l u e n c e ~ o f ~ t h e ~ m a l e ~ o n ~ l i t t e r ~}$ size in mice. J. Reprod. Fert., 7: $107-$ 1]1.

Gelderblom, W.C.A., Kriek, N.P.J., Marasas, W.F.O. and Thiel, P.G. (1991). Toxicity and carcinogenicity of the Fusarium monilforme metabolite, fumonisin B., in rats. Carcinogenesis, 12: 1247-1251.

Harrison, L.R., Colvin, B.M., Greene, J.T., Newman, L.E., and Cole, J.R. Jr. (1990). Pulmonary edema and hydrothorax in swine produced by fumonisin $\mathrm{B}_{\text {; }}$, a toxic metabolite of Fusarium moniliforme. J. fet. Dikgn. Invest., 2: 217-221. 
Javed, 'T., Richard, J.L., Bennett, G.A., Dombrink-Kurtzman, M.A., Bunte, R.M., Koelkebeck, K.W., Côté, L.M., Leeper, R.W. and Buck, W.B. (1993). Embryopathic and embryocidal effects of purified fumonisin B or Fusarinm proliferam culture material extract on chicken embryos. Mycopalhologia, 123: $185-193$.

Jayaraj, A.P., Murti, A.S.. Sreenivasamurthy, V. and Parpia, H.A.B., (1968). Toxic effects of aflatoxin on the test is of albino rats. J. Anat Soc Inclia, 17: 101-104.

Kellerman, T.S., Marasas, W.F.O., Thiel, P.G., Gelderblom, W.C.A., Cawood, M. and Coetzer, J.A.W. (1990). Leukoencephalomalacia in two horses induced by oral dosing of fumonisin B Onderstepoort J. Vet. Res., 57:269-275.

Marasas, W.F.O., Nelson, P.E. and Toussoun, T.A. (1984). loxigenic Fusarim species: Identity and mycotoxicology. University Park; Penn. Penn. State Ĺniv. Press, 328pp.

Marasas, W.F.O., Jaskiewicz, K., Venter, F.S. and Van Schalkwyk, D.J. (1988). Fusarium moniliforme contamination of maize in oesophageal cancer areas in Transkei. S. Afr: Med.J., 74:110-114.

Nelson, P.E., Desjardins, A.E. and Plattner, R.D. (1993). Fumonisins, mycotoxins produced by Fusarium species: Biology, chemistry, and significance. -1nnu Rev. Phytopathol. 31:233-252.
Nelson, P.E., Plattner, R.D., Shackelford, D.D. and Desjardins, A.E. (1991). Production of fumonisins by Fusarium moniliforme strains from various substrates and geographic areas. Appl. Emviron. Microbiol, 57:2410-2412.

Ortavant, R. (1959). Spermatogenesis and morphology of the spermatozoon. In: Reproduction in Domestic Animals, Coles. H.H. and Cupps, P.T. (Eds.). Acadenic Press Inc., New York: 1-50.

Panda, P.C., Sreenivasamurthy, V. and Parpia, H.A.B. (1970). Eflect of aflatoxin 13 on reproduction in rats. J. Food Sci. and Technol., 7: 20-22.

Petzinger, F. and Weidenbach, A. (2002). Mycotoxins in the food chain: the role of ochratoxins. Livestock Production Science, 76:245-250.

SAS Institute Inc (1999). SASAPAT User's Guide. Version 8 for wi ows. SAS Institute Inc.. SAS Campus Drive, Cary. Nortl Carolina, USA.

Shephard, G. S., Thiel, P. G., Stockenström, S. and Sydenham, E. W. (1996). Worldwide survey of lumonisin contamination of corn and corn-based products. J. Assoc. (Iff. Anal. Chem. Int., 79:671-687.

Swierstra, E.E. (1966). Structural composition of Shorthorn bull testes and daily spermatozoa production as sovientruin determined by quantitative testicular histology. Can. I. Anim. Sci., 46: $107-$ 119. 
Swierstra, E.E. and Fotte, R.H. (1963). Cytology and kinetics of spermatogenes is in the rabbit. J. Reprod. Fert. 5: 309-322. moniliforme culture material in rats and the biodistribution of [14C] fumonisin

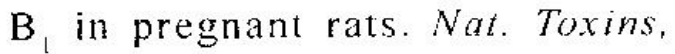
4:24-33.

\section{Voss, K.A., Bacon, C.W., Norred, W.P., Chapin,} R.E., Chamberlain, W.J, Plattner, R.D. and Meredith, F.I. (1996). Studies on the reproductive effects of Fusarium 